\title{
An Efficiency Assessment of Tuberculosis Treatment on Health Centers: A Data Envelopment Analysis Approach
}

\author{
Arnold P. Dela Cruz ${ }^{1,2}$, Gilbert M. Tumibay ${ }^{3}$ \\ ${ }^{1}$ Nueva Ecija University of Science and Technology, Cabanatuan, Philippines \\ ${ }^{2}$ Graduate School-Angeles University Foundation, Angeles, Philippines \\ ${ }^{3}$ Angeles University Foundation, Angeles, Philippines \\ Email: arnold@neust.edu.ph, tumibay.gibo@auf.edu.ph
}

How to cite this paper: Cruz, A.P.D. and Tumibay, G.M. (2019) An Efficiency Assessment of Tuberculosis Treatment on Health Centers: A Data Envelopment Analysis Approach. Journal of Computer and Communications, 7, 11-20.

https://doi.org/10.4236/jcc.2019.74002

Received: March 6, 2019

Accepted: April 7, 2019

Published: April 10, 2019

Copyright $\odot 2019$ by author(s) and Scientific Research Publishing Inc. This work is licensed under the Creative Commons Attribution International License (CC BY 4.0).

http://creativecommons.org/licenses/by/4.0/

\section{(c) (i) Open Access}

\begin{abstract}
This study utilized Data Envelopment Analysis (DEA) in assessing the efficiency of health center in tuberculosis (TB) treatment. Assessing the efficiency of health center treating TB is a vital and sensitive topic, because there is a cumulative amount of public funds devoted to healthcare. In this research, a DEA model has been correlated to evaluate and assess the efficiency of 17 health centers. The researchers selected the health budget and the number of health workers as input variables likewise, the number of people served, number of TB patients served, and TB patients treated (\%) as output variables. Based on the result of the study, only five (5) health centers out of seventeen (17) have $100 \%$ efficiencies throughout the 2 years period. It is recommended that other health centers should learn from their efficient peers recognized by the DEA model so as to increase the overall performance of the healthcare system. Likewise, health centers should integrate Health Information Technology to deliver healthier care for their patients.
\end{abstract}

\section{Keywords}

Data Envelopment Analysis, Health Center, Efficiency, Tuberculosis

\section{Introduction}

In Philippines, the Health Center (HC) is the immediate health care facility. It provides vital health services to the community, particularly those belonging to the grassroots level. The HC has a significant share of establishing a healthy community, because it has several purposes in serving different clients, like prenatal care, immunizations, monitoring of morbidity, and as part of referral system [1]. 
The basic goals followed by many countries are to heighten and advance their health system in terms of efficiency and quality services. In this circumstance, an essential reason is to encourage research along the efficiency of health focus to come with the best dissemination and utilization of medical services assets and to distinguish the issues that influence their efficiency and ability to convey high-quality services to the community. Efficiency is defined as "the relationship between the goods and services consumed and goods and services produced, or what is the same, for services rendered (outputs) in relation to the resources used for this purpose (inputs)" [2].

Considering the efficiency of the healthcare system is a challenging process which frequently encounters technical problems. Beginning with the health status of the people, which affects the productivity level, socioeconomic stability or welfare level, increasing the efficiency of healthcare services is a permanent objective, which becomes enormously imperative to the countries with small or average social development file.

The systematic reporting and collection of evidence and facts about the quality, usefulness, and efficiency of health departments is a common procedure. The performance data on health care services are regularly collected and reported. Through assessments, good practice providers can be used and identified as standards for refining the quality, efficiency, and success of related programs brought by other providers [3] [4].

Data Envelopment Analysis (DEA) has developed as a prevalent and effective method for measuring the efficiency of decision-making units in the health sector. There have been a number of studies on assessing the efficiency of health centers and hospitals by using DEA in different settings [5]. According to Liu [6], data envelopment analysis has been widely applied in many diverse areas such as banking, education, science, service industries, engineering, and healthcare, as well as in assessments of the country and regional performances. Around 2000 papers have been published in the same database during the period 2010 to 2014. As reported by $\mathrm{Liu}, \mathrm{Lu}$, and $\mathrm{Lu}$, all papers have enclosed a series of decision analysis applications involving hospitals, airports, schools, banks, hotels, and even countries and regions. Due to the strong characteristics and varied practical uses in microeconomics as well as in macroeconomics, the DEA method has been getting thorough consideration and has increasingly developed into a larger and academically acknowledged discipline.

Several studies were done to measure the efficiency in primary health care, and hospitals using DEA. Authors in [7] utilized DEA to measure the extent of technical efficiency of public health centers in Ghana. Similarly, researcher in [8] assessed the technical efficiency of health posts in rural Guatemala, while [9] assessed the application of DEA window analysis in the operational efficiencies of established branched hospitals and [10] looked into the technical efficiency of public health centers in the three districts in Ethiopia.

This study although similar to the researches reviewed in terms of the utilization of the DEA in health centers, is different as to addressing the efficiency of 
health centers focused on treating a specific disease which is one of the feared contagious diseases, the Tuberculosis. Also, this study will contribute to the existing knowledge of DEA studies in the Philippines, since there is dearth of researches pertaining to this model in health centers in the country.

This research delivers a great performance methodology with a complete and reliable description of data envelopment analysis. DEA provides the best methodology for healthcare workers to relative performance assessment. It is a comprehensible and very powerful analytic tool by which health care workers can assess comparative performance in their health centers. The information that can be gathered from DEA can also become the guide of health care workers for the health center and program development. In this paper, DEA evaluated the efficiency of the seventeen (17) health centers to analyze the most efficient in TB treatment which served as a benchmark for the inefficient health center. One of the variables considered to determine the efficiency of a certain health center is the minimal number of people who are infected with Tuberculosis (TB) disease. World Health Organization (WHO) stated that "Tuberculosis is one of a contagious disease which spreads through the air. When infectious person cough, sneeze, talk or spit, they transmit the disease-causing germs into the air which is inhaled with air and transmitted to another person" [11].

\section{Methodology}

The Data Envelopment Analysis is one of the most common approaches used in assessing the efficiency of DMUs. "The main objective of the DEA model is to find a limit for efficiency formed by those combinations of resources which optimize the number of products made by minimizing production costs. Then, with this limit, it assesses the relative efficiency of the combinations of resources that do not belong to it" [12]. DEA is a non-parametric method which classifies an efficiency boundary where only the efficient DMUs are cited by using linear programming techniques. Sultan [13] stated that linear programming is the optimization of an outcome based on some set of constraints using a linear mathematical model. According to [14], "Linear Programming is also a special technique for determining the optimum combination of scarce resources in the attainment of some objectives of economic or other nature".

\subsection{Data Source}

The study was conducted in Cabanatuan City, Nueva Ecija Philippines under the Rural Health Unit of Mabini Homesite (RHU-Mabini Homesite). The data for 17 health centers for 2016-2017 have been extracted from the Cabanatuan City Health Office database. This ratifies the comparability and accuracy of data, which are important features in the DEA model.

The Office of the City Mayor through the director of the City Health Office allowed the researchers to use the information from their database. To validate, the researchers also conducted a series of interviews. 


\subsection{Data Envelopment Analysis}

The Data Envelopment Analysis is the most common method used in assessing the efficiency of a set of DMUs. DEA has various strong points that make it the best and powerful tool for determining comparative efficiency between areas thus, determining rankings.

The DEA Model was developed by Charnes, Cooper, and Rhodes. It is a very advantageous methodology for specific case as it measures the productivity and efficiency connected to organizational units, like hospitals [15].

DEA uses techniques of linear programming to assess the efficiency scores of each health center. Health centers that are inefficient have a score of less than $100 \%$ or less than 1 , while efficient health centers have an efficiency score of $100 \%$ or 1 . The three (3) main advantages of DEA: 1) It simply includes a lot of inputs and outputs less the requirement for measurement of common denominator. It is the most appropriate methods in evaluating the efficiency of health centers using several inputs to create many outputs. 2) It offers specific input and output objectives that would make an inefficient health center relatively efficient. Additionally, it classifies efficient "peers" for those health centers that are not efficient. It supports inefficient health centers to follow the efficient group of their peers so as to increase their efficiency. 3) It helps to classify both the sources and levels of inefficiency, hence, providing direction on corrective actions to be taken.

In summary, DEA is a model that estimates the effectiveness and it might be characterized as an expansion of the straightforward input/output analysis ratio which is precisely summed up to work with multiple inputs and outputs. DEA utilizes numerical models (linear programming) to examine the efficiency constraint. This limit conveys a reference for judging, similarly, the results of the rest of the units don't have a place with the boiling point [16].

\subsubsection{DEA Formulation Model}

The developed model by Charnes, Cooper, and Rhodes is the most recognized DEA model formulation that has been modified by Banker, Charnes, and Cooper [17]. The model is drafted as follows:

For each $D M U_{p} \quad p=1,2, \cdots$

$$
\text { Maximize } E_{p}=\frac{\sum_{i} y_{p i} w_{i}}{\sum_{j} x_{p j} v_{j}}
$$

Subject to:

$$
\begin{aligned}
& \frac{\sum_{i} y_{p i} w_{i}}{\sum_{j} x_{p j} v_{j}} \leq 1 \text { for } k=1,2, \cdots, K \\
& E_{p}=H C \text { efficiency }(p=1,2, \cdots, K) \\
& w_{i} \geq \varepsilon \text { for } i=1,2, \cdots, I \\
& v_{j} \geq \varepsilon \text { for } j=1,2, \cdots, J
\end{aligned}
$$




$$
\begin{aligned}
& x_{k j}=\text { input value } j \text { for } D M U_{k} \\
& y_{k i}=\text { output value } i \text { for } D M U_{k} \\
& \varepsilon=a \text { small constant }
\end{aligned}
$$

These formulas are used to measure the estimated technical efficiency of each $\mathrm{HC}$ as compared to the relative efficiency of the other HCs encompassing the population.

\subsubsection{Decision Variables}

$v_{j}$ Weight of input $j$ (unitless)

$w_{i}$ Weight of output $i$ (unitless)

\section{Results and Discussions}

The Health Center efficiency was determined with the use of Data Envelopment Analysis. The researchers used the model of Charnes, Cooper, and Rhodes (CCR) using input-oriented and output oriented.

Table 1 presents the variables used in assessing the efficiency of the health center under the RHU-Mabini Homesite. The seventeen (17) health centers as Decision-Making Units (DMUs); health budget, and the number of health workers as input; on the other hand, a number of people served, a number of TB patients served, and TB patients treated (\%) as output. The data for the year

\begin{tabular}{|c|c|c|c|}
\hline & DMU & Input & Output \\
\hline 1 & BANTUG BULALO & \multirow{17}{*}{$\begin{array}{l}\text { Health Budget } \\
\text { Number of } \\
\text { Health Worker }\end{array}$} & \multirow{17}{*}{$\begin{array}{c}\text { Number of People Served } \\
\text { Number of TB Patient's Served } \\
\text { TB Patient's Treated (\%) }\end{array}$} \\
\hline 2 & BARRERA DISTRICT & & \\
\hline 3 & CARIDAD & & \\
\hline 4 & DICARMA & & \\
\hline 5 & DIONISIO S. GARCIA & & \\
\hline 6 & H. C. CONCEPCION & & \\
\hline 7 & IMELDA DISTRICT & & \\
\hline 8 & M. S. GARCIA & & \\
\hline 9 & MABINI EXTENSION & & \\
\hline 10 & MABINI HOMESITE & & \\
\hline 11 & MAGSAYSAY DISTRICT & & \\
\hline 12 & PADRE CRISOSTOMO & & \\
\hline 13 & SAN JUAN POB. & & \\
\hline 14 & SAN ROQUE SUR & & \\
\hline 15 & SANTA ARCADIA & & \\
\hline 16 & SUMACAB ESTE & & \\
\hline 17 & VILLA OFELIA & & \\
\hline
\end{tabular}
2017 of the health center are shown in Table 2.

Table 1. Variables used in measuring the efficiency of HC in TB treatment. 
Table 2. Health center data for the year 2017.

\begin{tabular}{|c|c|c|c|c|c|c|}
\hline \multirow[b]{2}{*}{ No. } & \multirow{2}{*}{$\begin{array}{c}\text { DMUs } \\
\text { Health Center }\end{array}$} & \multicolumn{2}{|c|}{ Input } & \multicolumn{3}{|c|}{ Output } \\
\hline & & $\begin{array}{l}\text { Health } \\
\text { Budget }\end{array}$ & $\begin{array}{l}\text { No. of } \\
\text { Health } \\
\text { Worker }\end{array}$ & $\begin{array}{l}\text { No. of } \\
\text { People } \\
\text { Served }\end{array}$ & $\begin{array}{c}\text { No. of TB } \\
\text { Patient's } \\
\text { Served }\end{array}$ & $\begin{array}{c}\text { TB } \\
\text { Patient's } \\
\text { Treated (\%) }\end{array}$ \\
\hline 1 & BANTUG BULALO & 271,274 & 4 & 2486 & 5 & 100 \\
\hline 2 & BARRERA DISTRICT & 511,576 & 3 & 5589 & 23 & 100 \\
\hline 3 & CARIDAD & 78,531 & 3 & 1960 & 5 & 100 \\
\hline 4 & DICARMA & 276,552 & 3 & 4659 & 5 & 80 \\
\hline 5 & DIONISIO S. GARCIA & 388,979 & 3 & 7359 & 24 & 83 \\
\hline 6 & H.C. CONCEPCION & 452,366 & 3 & 4201 & 6 & 100 \\
\hline 7 & IMELDA DISTRICT & 250,141 & 3 & 4161 & 14 & 79 \\
\hline 8 & M. S. GARCIA & 310,690 & 3 & 4857 & 13 & 92 \\
\hline 9 & MABINI EXTENSION & 390,000 & 3 & 3447 & 5 & 100 \\
\hline 10 & MABINI HOMESITE & 349,400 & 4 & 4490 & 11 & 100 \\
\hline 11 & MAGSAYSAY DISTRICT & 175,845 & 3 & 4672 & 13 & 85 \\
\hline 12 & PADRE CRISOSTOMO & 228,458 & 3 & 4179 & 10 & 100 \\
\hline 13 & SAN JUAN POB. & 347,717 & 3 & 6950 & 16 & 88 \\
\hline 14 & SAN ROQUE SUR & 121,006 & 3 & 1410 & 7 & 86 \\
\hline 15 & SANTA ARCADIA & 297,697 & 3 & 4782 & 12 & 83 \\
\hline 16 & SUMACAB ESTE & 434,539 & 3 & 4283 & 7 & 100 \\
\hline 17 & VILLA OFELIA & 148,764 & 3 & 1372 & 2 & 100 \\
\hline
\end{tabular}

A relative efficiency formula combining several inputs and outputs can be presented, and the DEA model which allows relative efficiency measures to be determined can be developed. The data made presented by explaining the model in applying the method can also be deliberated.

Measure for Relative Efficiency:

$$
\text { Efficiency }=\frac{\text { weighted sum of output }}{\text { weighted sum of input }}
$$

This is written as:

$$
\text { Efficiency of } \mathrm{HC}=\frac{y_{1 j} w_{1}+y_{2 j} w_{2}+y_{3 j} w_{3}}{x_{1 j} v_{1}+x_{2 j} v_{2}}
$$

The efficiency of HC 1 (DMU: Bantug Bulalo) where the data extracted from the year 2017 by relating the model that was stated in Equations (1) \& (2) was achieved by solving the following model:

$$
\operatorname{Max} E_{p}=\frac{2486 w_{1}+5 w_{2}+100 w_{3}}{271274 v_{1}+4 v_{2}} \leq 1
$$

Subject to: 


$$
\begin{aligned}
& \frac{2486 w_{1}+5 w_{2}+100 w_{3}}{271274 v_{1}+4 v_{2}} \leq 1 \quad(\text { HC } 1) \\
& \frac{5589 w_{1}+23 w_{2}+100 w_{3}}{511576 v_{1}+3 v_{2}} \leq 1 \quad(\text { HC } 2) \\
& \frac{1960 w_{1}+5 w_{2}+100 w_{3}}{78531 v_{1}+3 v_{2}} \leq 1 \quad(\text { HC } 3)
\end{aligned}
$$

Same procedure will be done for all Health Center $(\mathrm{HC})$

$$
\begin{aligned}
& w_{i} \geq \varepsilon \\
& v_{j} \geq \varepsilon
\end{aligned}
$$

In the above model, the w's and v's are variables of the problem and to avoid any input or output being entirely disregarded in defining the efficiency, the variables are forced to be greater than or equal to certain small positive measure. The description to the above model provides a value $E_{p}$, the HC 1 efficiency, and the weights generate that efficiency. If $E_{p}$ is equal to one $\left(E_{p}=1\right)$, then HC 1 is efficient compared to the others, but if $E_{p}$ is less than one $\left(E_{p}<1\right)$ then some other HCs are more efficient than HC 1, even when the weights are selected to maximize HC 1's efficiency.

To solve the DEA model which is a fractional linear program, it is required to translate it into linear form to apply the linear programming methods. The model presented below.

Resultant Linear Program:

$$
\operatorname{Max} E_{p}=\sum_{i} y_{p i} w_{i}
$$

Subject to:

$$
\begin{gathered}
\sum_{j} x_{o j} v_{j}=1 \\
\sum_{i} y_{o i} w_{i}-\sum_{i} x_{o j} v_{j} \leq 0 \quad \text { (for all HC in 2017) } \\
w_{i} \geq \varepsilon \\
v_{j} \geq \varepsilon
\end{gathered}
$$

By solving Equations (8), (9), and (10), the target unit efficiency in a set can be achieved. The result of this linear program offers a measure of the relative efficiency of the target unit and the weights generate that efficiency. The weights are the most advantageous from the target unit perspective. It is required to answer a linear program directing on each unit to attain the efficiencies of the whole set of units. The results for the 17 health centers are illustrated in Table 3. These results show that some of the health centers remained constant at $100 \%$ efficiency for two (2) years. The health centers that have the $100 \%$ efficiency were Caridad, Dionisio S. Garcia, Magsaysay District, San Juan Pob., and Villa Ofelia and the remaining 12 health centers were classified as low efficiency in TB treatment. 
Table 3. Two year scale efficiency result of 17 health centers.

\begin{tabular}{|c|c|c|c|c|c|}
\hline \multirow{2}{*}{ No. } & \multirow{2}{*}{ Health Center (HC) } & \multicolumn{2}{|c|}{ Efficiency per Year } & \multirow{2}{*}{ Average } & \multirow{2}{*}{ Ranking } \\
\hline & & 2016 & 2017 & & \\
\hline 1 & BANTUG BULALO & 1.00 & 0.75 & 0.87 & 14 \\
\hline 2 & BARRERA DISTRICT & 0.92 & 1.00 & 0.96 & 7 \\
\hline 3 & CARIDAD & 1.00 & 1.00 & 1.00 & 1 \\
\hline 4 & DICARMA & 1.00 & 0.86 & 0.92 & 11 \\
\hline 5 & DIONISIO S. GARCIA & 1.00 & 1.00 & 1.00 & 1 \\
\hline 6 & H. C. CONCEPCION & 0.89 & 1.00 & 0.95 & 8 \\
\hline 7 & IMELDA DISTRICT & 0.96 & 0.89 & 0.92 & 12 \\
\hline 8 & M. S. GARCIA & 1.00 & 0.95 & 0.97 & 6 \\
\hline 9 & MABINI EXTENSION & 0.69 & 1.00 & 0.84 & 16 \\
\hline 10 & MABINI HOMESITE & 1.00 & 0.76 & 0.88 & 13 \\
\hline 11 & MAGSAYSAY DISTRICT & 1.00 & 1.00 & 1.00 & 1 \\
\hline 12 & PADRE CRISOSTOMO & 0.88 & 1.00 & 0.94 & 10 \\
\hline 13 & SAN JUAN POB. & 1.00 & 1.00 & 1.00 & 1 \\
\hline 14 & SAN ROQUE SUR & 1.00 & 0.89 & 0.95 & 8 \\
\hline 15 & SANTA ARCADIA & 0.86 & 0.88 & 0.87 & 15 \\
\hline 16 & SUMACAB ESTE & 0.69 & 1.00 & 0.84 & 17 \\
\hline 17 & VILLA OFELIA & 1.00 & 1.00 & 1.00 & 1 \\
\hline
\end{tabular}

\section{Conclusions and Recommendations}

This paper has presented a DEA model which consists of 2 inputs and 3 outputs to assess the efficiency of 17 health centers based on their TB treatment. The study revealed that only five (5) health centers out of seventeen (17) have $100 \%$ efficiencies throughout the 2 year period. The following reasons for such low efficiency in TB treatment of the health center are the high allotted health budget, and the high number of health workers for input relative to their output covered. As a result, in order to increase their efficiencies, the input for the health budget and the number of health worker for those health centers must be in proportion based on the number of people and TB patients served. According to the World Health Organization (WHO), "people with TB can infect up to $10-15$ other people through close contact over the course of a year. Without proper treatment, up to two-thirds of people with TB will die" [18]. In this situation, HCs need to be $100 \%$ efficient in terms of TB treatment to prevent spreading this chronic infectious disease. It is recommended that other health centers should learn from their efficient peers recognized by the DEA model and continue to investigate and evaluate the technique [19] they are using so as to increase the overall performance of their healthcare delivery system. 


\section{Conflicts of Interest}

The authors declare no conflicts of interest regarding the publication of this paper.

\section{References}

[1] Belciña, K.A. and Selisana, J.A. (2018) Lack of a Barangay Health Station. Bag-Ong Dalaguete Delegates.

[2] Aeca, A. (1997) Performance Indicators for Public Entities. Document No. 16, Series of Principles of Managerial Accounting, 2nd Edition, Madrid.

[3] Balf, F.R., Rezai, H.Z., Jahanshahloo, G.R. and Lotfi, F.H.F. (2012) Ranking Efficient DMUs Using the Tchebycheff Norm. Applied Mathematical Modelling, No. 36, 46-56.

[4] Barros, C.P., Managi, S. and Matousek, R. (2012) The Technical Efficiency of the Japanese Banks: Non-Radial Directional Performance Measurement with Undesirable Output. Omega, 40, 1-8. https://doi.org/10.1016/j.omega.2011.02.005

[5] Jat, T.R. and Sebastian, M.S. (2013) Technical Efficiency of Public District Hospitals in Madhya Pradesh, India: A Data Envelopment Analysis. Global Health Action, 6, 1. https://doi.org/10.3402/gha.v6i0.21742

[6] Liu, J.S., Lu, L.Y., Lu, W.M. and Lin, B.J. (2013) Data Envelopment Analysis 1978-2010: A Citation-Based Literature Survey. Omega, 41, 3-15.

https://doi.org/10.1016/j.omega.2010.12.006

[7] Akazili, J., Adjuik, M., Jehu-Appiah, C. and Zere, E. (2008) Using Data Envelopment Analysis to Measure the Extent of Technical Efficiency of Public Health Centers in Ghana. BMC International Health and Human Rights, 8, 11.

[8] Hernández, A.R. and San Sebastián, M. (2014) Assessing the Technical Efficiency of Health Posts in Rural Guatemala: A Data Envelopment Analysis. Global Health Action, 7, 23190. https://doi.org/10.3402/gha.v7.23190

[9] Jia, T. and Yuan, H. (2017) The Application of DEA (Data Envelopment Analysis) Window Analysis in the Assessment of Influence on Operational Efficiencies after the Establishment of Branched Hospitals. BMC Health Services Research BMC, 17, 265.

[10] Bobo, F.T., Woldie, M., Wordofa, M.A., Tsega, G., Agago, T.A., Wolde-Michael, K., Ibrahim, N. and Yesuf, E.A. (2018) Technical Efficiency of Public Health Centers in Three Districts in Ethiopia: Two-Stage Data Envelopment Analysis. BMC Research Notes, 11, 465. https://doi.org/10.1186/s13104-018-3580-6

[11] WHO (2010) Tuberculosis, Fact Sheet No. 104. https://www.who.int/en/news-room/fact-sheets/detail/tuberculosis

[12] Jacobs, R., Smith, P. and Street, A. (2006) Measuring Efficiency in Health Care. Analytic Techniques and Health Policy, Cambridge University Press, Cambridge.

[13] Sultan, A. (1993) Linear Programming: An Introduction with Applications. Academic Press, San Diego.

[14] Iwuagwu, C.C. (2000) Quantitative Methods for Business Application. Name Ventures Ltd., Owerri.

[15] Charnes, A., Cooper, W. and Rhodes, E. (1978) Measuring the Efficiency of Decision-Making Units. European Journal of Operational Research, No. 2, 429-441.

[16] Charnes, A., Cooper, W., Lewin, A. and Seiford, L. (1994) Data Envelopment Analysis. Theory, Methodology, and Applications. Kluwer Academic Publishers, Dor- 
drecht, Chapters 1-3.

[17] Banker, R.D., Conrad, R.F. and Strauss, R.P. (1986) A Comparative Application of Data Envelopment Analysis and Translog Method: An Illustrative Study of Hospital Production. Management Science, 32, 30-44.

[18] World Health Organization (2018) Tuberculosis. http://www.who.int/features/qa/08/en

[19] Subia, G. (2018) Comprehensible Technique in Solving Consecutive Number Problems in Algebra. Journal of Applied Mathematics and Physics, 6, 447-457. https://doi.org/10.4236/jamp.2018.63041 